\title{
DEGRADACIÓN DE RESIDUOS ACEITOSOS PROVENIENTES DE ACTIVIDADES MINERAS EN LA GUAJIRA, COLOMBIA
}

\author{
Carlos Julio Doria Argumedo'
}

${ }^{1}$ Magister en Química. Universidad de La Guajira. Riohacha-Colombia. Grupo de Investigación Territorios semiáridos del Caribe. cdoria@uniguajira.edu.co

\begin{abstract}
RESUMEN
En la actualidad la contaminación de los suelos por derrame de petróleo y sus derivados, se ha considerado como uno de los problemas ambientales más importantes. La adición de nutrientes a un suelo contaminado por hidrocarburos es una de las técnicas de biorremediación de mayor aplicación. En esta investigación se evaluó dicha técnica a escala piloto, a través de un diseño de 3 unidades experimentales con capacidad de $200000 \mathrm{~cm}^{3}$ que contenían una mezcla variable de suelo, aceites usados en las actividades de exploración y explotación de carbón, y excretas de ganado vacuno y caprino manteniendo una relación de 1:3 de suelo y aceite. La efectividad del proceso de biorremediación se determinó por medio de análisis del pH, porcentaje de humedad, temperatura, \% de aceite, N, P y número más probable de microorganismos degradadores de hidrocarburos totales, durante un período de experimentación de 120 días. Al final de la experimentación se obtuvo mayor efectividad de biorremediación en la unidad estimulada con excreta de ganado vacuno con un $65 \%$. La efectividad del proceso estuvo determinada por valores óptimos de temperatura $\left(24-29^{\circ} \mathrm{C}\right)$, humedad (11-20,6\%), pH (6,40 -8,30) y un crecimiento bacteriano de las especies Pseudomonas spp, Acinetobacter spp.y Bacillus spp experimento puede ser considerado como una alternativa de manejo y eliminación de residuos que puede ser aplicado a mayor escala, convirtiéndose en una alternativa viable desde los puntos de vista ambiental y económico.
\end{abstract}

Palabras clave: Aceites usados, Biorremediación, excreta de ganado, mina de carbón.

Recibido: 26 de Julio de 2017. Aceptado: 13 de Junio de 2018

Received: July 26th, $2017 . \quad$ Accepted: June 13th, 2018

\section{DEGRADATION OF OILY RESIDUES FROM MINING ACTIVITIES IN LA GUAJIRA, COLOMBIA}

\begin{abstract}
Today, the contamination of soils by oil spills and their derivatives has been considered one of the most important environmental problems. The addition of nutrients to a soil contaminated by Hidrocarburos is one of the most applied bioremediation techniques. This research evaluated the pilot-scale technique, through a design of 3 experimental units with capacity of $200000 \mathrm{~cm}^{3}$ containing a variable mixture of soil, oils used in the exploration and exploitation of coal and excreta of cattle and goats maintaining a ratio of 1:3 soil and oil. The effectiveness of the bioremediation process was determined by means of $\mathrm{pH}$ analysis, percentage of humidity, temperature, \% of oil, N, $P$ and the most probable number of total hydrocarbon degradation microorganisms, during an experimental period of 120 days. At the end of the experimentation was obtained more bioremediation effectiveness in the unit stimulated with excreta of cattle of $65 \%$. The effectiveness of the process was determined by optimal temperature values (24- $29{ }^{\circ} \mathrm{C}$ ), humidity (11-20.6\%), $\mathrm{pH}(6.40-8.30$ ) and bacterial growth of the species Pseudomonas spp., Acinetobacter spp. and Bacillus spp. The experiment can be considered as an alternative of management and elimination of residues that can be applied on a larger scale, becoming a viable alternative from the environmental and economic points of view.
\end{abstract}

Key words: Used oils, bioremediation, excreta de livestock, coal mine

Cómo citar este artículo: C. J. Doria Argumedo, "Degradación de residuos aceitosos provenientes de actividades mineras en la Guajira, Colombia", Revista Politécnica, Año 14, vol. 14, no. 26, pp. 42-51, 2018. https://doi.org/10.33571/rpolitec.v14n26a4 


\section{INTRODUCCIÓN.}

La minería de carbón a cielo abierto en la región de La Guajira, al norte de Colombia, constituye la actividad productiva más importante asociada a la generación de empleo y actividades comerciales subsecuentes a las etapas de exploración y explotación. En las operaciones de extracción del carbón por parte de la empresa El Cerrejón, la maquinaria pesada y liviana requiere la utilización de aceites lubricantes, hidráulicos y torque; según el tipo de actividad. Anualmente el complejo minero requiere en promedio un equivalente a 700 mil galones de aceite, de los cuales se recupera el $65 \%$ del producto usado que son devueltos al proveedor, garantizándose así el retiro de las instalaciones de la empresa y la recuperación del aceite usado de manera permanente en las operaciones (Cerrejón, 2011). El 35\% restante del aceite usado no recuperado se le conoce como residuo aceitoso, el cual es generado en los procesos de mantenimiento, limpieza, y eventuales fugas de los equipos o derrames en el momento de la manipulación del producto (Gualdrón, 2010), considerándose así un material de desecho; convirtiéndose en un contaminante ambiental de origen antropogénico derivado del petróleo.

La composición de la base orgánica de los aceites lubricantes está formada de cientos de miles de compuestos orgánicos, siendo la gran mayoría compuestos aromáticos polinucleares (PNA). Algunos de estos PNA (principalmente estructuras de 4,5 y 6 anillos) son considerados cancerígenos como el benzopireno. Los aceites son muy utilizados en el sector industrial para la lubricación de maquinaria pesada y liviana y que después de cumplida sus funciones queda un aceite usado mezclado que posee características físico-químicas generales, así como olor penetrante, color oscuro y de alta viscosidad. Dependiendo de la aplicación que se les vaya a dar, los aceites poseen composiciones muy variables, en todos los casos como consecuencia de su utilización se degradan perdiendo las cualidades que les hacían operativos, llegado éste punto se hace necesaria su sustitución por otros nuevos, generándose un residuo que puede ser variable en cantidad y composición, dependiendo de la procedencia por derrames de hidrocarburos principalmente del petróleo y sus derivados, Que ligado a su procedencia puede ser variable en cantidad y composición (4). Las características del aceite usado pueden variar dentro de un amplio margen dependiendo de la procedencia y aplicación del aceite, en general las contaminaciones tienen su origen en compuestos derivados de la degradación de los aditivos en subproductos de combustión incompleta, polvo, partículas metálicas 0 en contaminaciones exteriores por mal mantenimiento 0 mal almacenamiento del aceite (agua, disolventes, etc.) (5). Su composición química presenta una serie de contaminantes como son: azufre, compuestos clorados y metales pesados que determinan sus características toxicas y peligrosas. La mayoría de los aceites usados contienen compuestos tóxicos los cuales al quemarse son liberados a la atmósfera, esto hace necesario la implementación de políticas dirigidas a su disposición final y a los métodos usados para la combustión de los mismos (6). El suelo mezclado con aceite usado se convierte en un problema de contaminación, porque se presenta un movimiento de contaminantes y compuestos tóxicos y peligrosos, a través del medio siendo similar al movimiento de energía y nutrientes por el ecosistema y a mayor escala por la biosfera (7). La biorremediación es una tecnología sustentable que acelera la degradación del petróleo en suelos contaminados y posee una relación costo beneficio favorable frente a otros métodos de remediación (8). La biorremediación de hidrocarburos derivados del petróleo depende de diversos factores: presencia de una población microbiana activa, estructura y concentración del contaminante, disponibilidad de oxígeno y nutrientes, tipo de suelo, cantidad de materia orgánica $(\mathrm{MO})$ y minerales presentes en el mismo, entre otros (9). La técnica de Relleno en tierra (Landfarm) es una forma de biorremediación, similar a la biorecuperación, que mezcla cantidades de tierra limpia con los cortes contaminados hasta que la mezcla compuesta tenga un hidrocarburo de petróleo total (TPH) nivelado debajo de una regulación ambiental y de salu. El Lanfarm es una tecnología de remediación superficial para suelos que reduce las concentraciones de los constituyentes hidrocarburados por medio de la biodegradación (10). Diversos estudios permiten hoy en día establecer una lista de 160 géneros de microorganismos que degradan los hidrocarburos (11) los consorcios más empleados contienen las especies Flavobacterium, Achromobacter, Rhodococcus, Micrococcus, Bacillus, Corynebacterium, Pseudomonas, Aeromonas, 
Acinetobacter y en menos ocasiones Mycobacterium, Aspergillus, Fusarium, Penicillium, Rhodotorula y Candida (12). Las bacterias son más empleadas que los hongos y las levaduras (13).

Considerando lo expuesto anteriormente, en el presente trabajo se estudió, a escala experimental, Un proceso de biorremediación de suelos contaminados con aceites usados, por su uso en actividades mineras, a partir de la enmienda orgánica con excreta de ganado vacuno como una posible alternativa de solución a la contaminación de suelos de la región en los cuales se han dispuesto derivados de hidrocarburos.

\section{MATERIALES Y MÉTODO}

\subsection{Diseño,caracterización de los terrarios y preparación de sustratos.}

Se construyeron tres recipientes rectangulares en acero inoxidable, con las dimensiones de: $100 \mathrm{~cm}$ de largo, $40 \mathrm{~cm}$ de ancho y $50 \mathrm{~cm}$ de profundidad (capacidades de $200000 \mathrm{~cm}^{3}$ ); con orificios laterales de 3/8" para el drenaje. Las unidades experimentales fueron ubicadas en el campus universitario de la Universidad de La Guajira, ubicado a $5 \mathrm{~km}$ de la ciudad de Riohacha

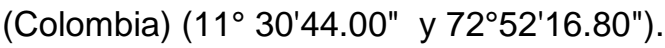

El Terrario No 1: Contuvo sustrato conformado por $18000 \mathrm{~cm}^{3}$ de suelo, $6000 \mathrm{~cm}^{3}$ de residuo aceitoso y $5 \mathrm{~kg}$ de excreta de ganado vacuno; manteniendo la relación de 1:3 de residuo aceitoso y suelo.

El Terrario No 2: El sustrato estuvo conformado por $18000 \mathrm{~cm}^{3}$ de suelo, $6000 \mathrm{~cm}^{3}$ de residuo aceitoso y $5 \mathrm{~kg}$ de excreta de ganado caprino; manteniendo la relación de 1:3 de residuo aceitoso y suelo.

El Terrario No 3, definido como control, contuvo un sustrato conformado por $18000 \mathrm{~cm}^{3}$ de suelo y $6000 \mathrm{~cm}^{3}$ de residuo aceitoso; manteniendo la relación de 1:3 de residuo aceitoso y suelo.

El suelo utilizado fue obtenido del campus de la Universidad de La Guajira, la cual se encuentra en Riohacha ubicada en la parte central izquierda del Departamento de La Guajira, posee una extensión territorial $3084 \mathrm{~km} 2$ y una altitud de $5 \mathrm{msnm}$, la mayoría del terreno se compone de suelo arcilloso y arenoso, especialmente en las costas. La mayor parte del año, la ciudad presenta un clima cálido uniforme con leves diferencias entre el día y la noche, tiene una temperatura media anual de 28 grados Celsius (14). El residuo aceitoso fue tomado del depósito de aceite usado de uno de los talleres de mantenimiento de maquinaria pesada de la mina de carbón; y las excretas de ganado vacuno y caprino procedentes de las comunidades indígenas wayuu ubicadas alrededor del campus de la Universidad de La Guajira, dedicadas al pastoreo. El sustrato contenido en cada terrario fue homogenizado y humedecido semanalmente, con el fin garantizar la aireación. Los suelos de esta zona se han evolucionado a parir de sedimentos moderadamente finos, bien drenados, de textura franco arenosas, francas, franco arcillo arenosa, franco arcillosas y arcillosas, con baja retención e humedad y $\mathrm{pH}$ moderadamente alcalino $(7,2-8,2)$ atribuidos a materiales aluviales ricos en $\mathrm{CaCO}_{3}$ (15).

Tabla 1. Métodos analíticos aplicados a las muestras de sustrato

\begin{tabular}{|l|l|}
\hline \multicolumn{1}{|c|}{ Parámetro } & \multicolumn{1}{c|}{ Método } \\
\hline Temperatura & Medición con sonda \\
\hline Textura & Método de bouyoucos \\
\hline Peso específico & $\begin{array}{l}\text { Medición con balanza } \\
\text { analítica }\end{array}$ \\
\hline Humedad & Secado a $105^{\circ} \mathrm{C}$ \\
\hline Fósforo & $\begin{array}{l}\text { Fusión } \mathrm{NaNO}_{3} / \mathrm{KNO}_{3} \\
\text { cuantificación de azul } \\
\text { colorimétrica de } \\
\text { de molibdeno }\end{array}$ \\
\hline Nitrato & $\begin{array}{l}\text { Extracción con cloruro } \\
\text { de potasio 2N y } \\
\text { cuantificación potencio } \\
\text { métrica }\end{array}$ \\
\hline $\begin{array}{l}\text { Contenido } \\
\text { aceite }\end{array}$ & $\begin{array}{l}\text { Extracción con hexano } \\
\text { y evaporación con } \\
\text { rotovapor }\end{array}$ \\
\hline $\begin{array}{l}\text { Crecimiento } \\
\text { basteriano }\end{array}$ & $\begin{array}{l}\text { Fermentación en } \\
\text { tubos múltiples-NMP }\end{array}$ \\
\hline
\end{tabular}

\subsection{Muestreo de sustratos.}

Se tomaron 4 muestras de sustrato de aproximadamente $100 \mathrm{~g}$ en cada terrario, mensualmente por cuatro meses (120 días), en 
bolsas plásticas las cuales fueron transportadas al laboratorio y refrigeradas a una temperatura aproximada de $4,0{ }^{\circ} \mathrm{C}$ hasta su posterior análisis. en las próximas seis horas

\subsection{Análisis físico, químico y microbiológico.}

Las variables correspondientes a los análisis fueron: temperatura, textura, $\mathrm{pH}$, peso específico, humedad, fósforo como ortofosfato, nitrógeno como nitrato, contenido de aceites, y crecimiento bacteriano. Los análisis fueron realizados siguiendo las técnicas y las metodologías descritas en Métodos Analíticos del laboratorio de Suelos (16), las cuales se indican en la tabla 1.

\subsection{Análisis estadístico.}

Para el análisis estadístico se aplicaron varios criterios como la prueba de criterio de Chauvenet, pruebas de medias normales, con varianza y medias desconocidas $t$-Student, coeficiente de correlación lineal, series de tiempo, para el caso de las concentraciones en los diferentes períodos de monitoreo, análisis de correlación entre concentración de iones en los diferentes terrarios con el objeto de determinar posibles asociaciones.

\section{RESULTADOS}

En la Tabla 2 se indican las propiedades de textura y peso específico del suelo utilizado en el proceso de biodegradación de los aceites usados. La textura moderadamente gruesa del suelo fue considerado como un factor no limitante en el proceso de degradación debido a que la adición del material de excreta de ganado le proporciona al sustrato mayor capacidad de retención de humedad y nutrientes. La textura del suelo y su contenido químico es importante en el proceso de biodegradación. Estos parámetros afectan la capacidad de retención de agua y aceite, ya que perturban la permeabilidad, el contenido de humedad y la densidad del mismo, el tipo y número de microorganismos y el acceso de oxígeno (17). En la tabla 3 se indican el promedio de las variables físicas, químicas y mirobiológicas del sustrato antes del tiempo de biodegradación de los residuos aceitosos y en la Tabla 4 el promedio de las variables físicas, químicas y mirobiológicas del sustrato durante el tiempo de biodegradación de los residuos aceitosos; se observa que durante el proceso de degradación ocurre un aumento de las variables físicas que interfieren en el proceso de degradación del hidrocarburo como lo la temperatura el $\mathrm{pH}$ y la humedad. La oxidación de los hidrocarburos produce ácidos grasos que son utilizados por las bacterias o liberadas en el medio. Si este es el caso, el pH del medio disminuye. Esta acidificación se emplea como parámetro para evaluar la degradación, junto con el incremento de la población microbiana a lo largo del tiempo es el resultado del consumo de los hidrocarburos como fuente de carbono y energía (18). La disminución de la concentración de hidrocarburo en el medio puede ser un segundo indicador de la degradación. Si la población logra utilizar el contaminante como fuente de carbono, la concentración del mismo debe disminuir con el tiempo y ser reemplazado en el medio por nuevos metabolitos (19).

Tabla 2. Valores de la textura y peso específico del suelo utilizado en el proceso de biodegradación de los aceites usados.

\begin{tabular}{|l|c|}
\hline Textura & \\
$\%$ de arena & 60,45 \\
$\%$ de arcilla & 8,1 \\
$\%$ de limo & 31,50 \\
Clase textural & Franco arenoso \\
\hline Peso específico & $1,48 \mathrm{~g} / \mathrm{Kg}$ \\
\hline
\end{tabular}

\section{DISCUSION}

La temperatura de los tres terrarios presentó poca variabilidad en el tiempo y sin diferencias significativas $(p=1,00, p>0,05)$. Los valores de temperatura promedio en los tres terrarios por encima de los $24^{\circ} \mathrm{C}$ garantiza la actividad de los microorganismos (20). La biodegradación se ve favorecida en una rango de temperatura entre 25$37^{\circ} \mathrm{C}$, valores a los que se intensifica la actividad enzimática de los microorganismos acelerando al máximo los procesos de biodegradación. Cuando la temperatura es baja, la viscosidad de los hidrocarburos aumenta variando su solubilidad en agua y se disminuye la volatilización de algunas fracciones tóxicas que pueden afectar la actividad degradadora de los microorganismos (21). Con temperaturas muy altas, se incrementa la toxicidad de los hidrocarburos inhibiendo la actividad microbiana (22). 
Tabla 3. Valores promedio de las variables físicas, químicas y microbiológicas del sustrato antes del proceso de biodegradación de los residuos aceitosos.

\begin{tabular}{|l|c|c|c|}
\hline \multicolumn{1}{|c|}{ Variables } & \multicolumn{3}{|c|}{ Terrarios } \\
\hline & 1 & 2 & 3 \\
\hline $\begin{array}{l}\text { Temperatura } \\
\left({ }^{\circ} \mathrm{C}\right)\end{array}$ & 26,70 & 26,50 & 27,30 \\
\hline $\mathrm{pH}$ & 6,17 & 6,37 & 6,82 \\
\hline $\mathrm{Humedad}(\%)$ & 12,22 & 15,03 & 15,11 \\
\hline $\begin{array}{l}\text { Fósforo- } \mathrm{PO}_{4}{ }^{3-} \\
(\mathrm{mg} / \mathrm{Kg})\end{array}$ & 0,26 & 1,39 & 0,87 \\
\hline \begin{tabular}{l}
$\mathrm{Nitrógeno-}^{\mathrm{NO}_{3}^{-}(\mathrm{mg} / \mathrm{Kg})}$ \\
\hline Aceite (\%)
\end{tabular} & 0,16 & 0,39 & 0,45 \\
\hline $\begin{array}{l}\text { Bacterias } \\
\text { presentes } \\
\text { (NMP) }\end{array}$ & 10,10 & 10.54 & 10.99 \\
\hline
\end{tabular}

Tabla 4. Valores promedio de las variables físicas, químicas y microbiológicas del sustrato después del tiempo de biodegradación de los residuos aceitosos.

\begin{tabular}{|l|c|c|c|}
\hline \multicolumn{1}{|c|}{ Variables } & \multicolumn{3}{|c|}{ Terrarios } \\
\hline $\begin{array}{l}\text { Temperatura } \\
\left({ }^{\circ} \mathrm{C}\right)\end{array}$ & 27,80 & 27,70 & 27,75 \\
\hline $\mathrm{pH}$ & 7,87 & 7,37 & 7,52 \\
\hline Humedad (\%) & 15,52 & 17,07 & 17,41 \\
\hline $\begin{array}{l}\text { Fósforo- } \mathrm{PO}_{4}^{3-} \\
(\mathrm{mg} / \mathrm{Kg})\end{array}$ & 1,99 & 2,19 & 1,59 \\
\hline $\begin{array}{l}\text { Nitrógeno- } \\
\mathrm{NO}_{3}{ }^{-}(\mathrm{mg} / \mathrm{Kg})\end{array}$ & 0,66 & 0,69 & 0,83 \\
\hline Aceite $(\%)$ & 7,60 & 8,09 & 9,39 \\
\hline $\begin{array}{l}\text { Bacterias } \\
\text { presentes } \\
(\mathrm{NMP})\end{array}$ & 49304,29 & 10185,64 & 11968,25 \\
\hline
\end{tabular}

El rango de humedad de los terrarios estuvo entre $10-50 \%$ sin diferencias significativas $(p=1,166$, $p>0,05)$, manteniéndose en un porcentaje óptimo de $6-22 \%$ según Ecopetrol (23). Se presume que la frecuencia del riego y el material de excretas de ganado ayudaron a mejorar la capacidad de retención de humedad del suelo y controlar la variación de la temperatura. La humedad óptima para el crecimiento microbiano está entre el 50$70 \%$; la actividad biológica decrece mucho cuando la humedad está por debajo del $30 \%$; por encima del $70 \%$ el agua desplaza al aire en los espacio libres existentes entre las partículas, reduciendo la transferencia de oxígeno y produciéndose una anaerobiosis. Cuando las condiciones se hacen anaerobias se originan malos olores y disminuye la velocidad del proceso (24). El agua es el principal componente del protoplasma bacteriano y su suministro es esencial para el crecimiento y mantenimiento de los microorganismos (25). El contenido suelo-agua influye en la aireación (transporte de oxígeno), en la solubilidad de los constituyentes del suelo y en el pH (26). Poca humedad en el suelo da como resultado zonas secas y por lo tanto poca actividad de los microorganismos. Sin embargo demasiada humedad inhibe el intercambio de gases y da como resultado el desarrollo de zonas anaerobias y como consecuencia la eliminación de bacterias aerobias y el incremento de anaerobias facultativas (27). El pH durante el tiempo de biodegradación presentó poca variabilidad en los diferentes terrarios, con valores en el rango de 5,80 y 8,30, observándose mayores valores en el terrario No 1 indicado la favorabilidad de la excreta de ganado vacuno (Figura 1). Se observó un incremento

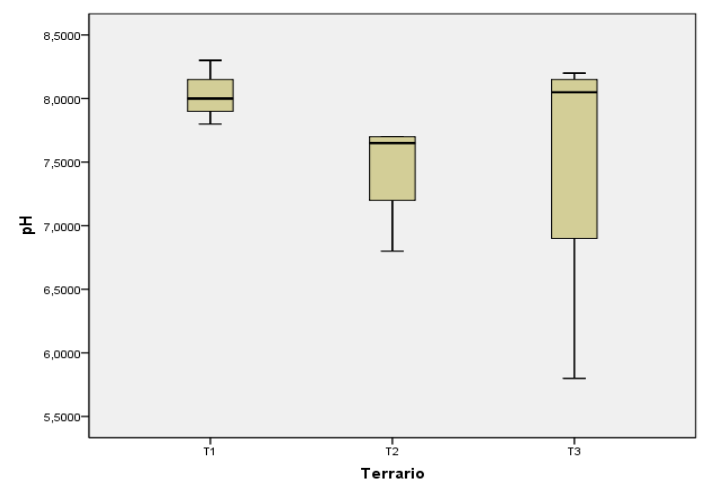

Figura 1. Variación del $\mathrm{pH}$ en los tres terrarios durante el tiempo de biodegradación de los residuos aceitosos

$\mathrm{El} \mathrm{pH}$ afecta las poblaciones microbianas, por la biodisponibilidad de fuetes de carbono y energía. A $\mathrm{pH}$ extremadamente alcalinos $\mathrm{o}$ extremadamente ácidos la biodegradación se hace lenta. Generalmente los suelos contaminados por hidrocarburos tienden a ser ácidos, lo cual limita el crecimiento y la actividad de los microorganismos. El rango óptimo para la biodegradación está entre 6 - 8 unidades de $\mathrm{pH}$. Sin embargo, para mantener una mejor capacidad degradante, por periodos de tiempo prolongados, el $\mathrm{pH}$ debe ser neutro, entre 7.4-7.8, evitando al máximo las fluctuaciones. 
Suler et al, 1977 (28) establecieron una relación entre los cambios de $\mathrm{pH}$ y la aireación de la mezcla, concluyendo que un proceso biodegradativo con la aireación adecuada conduce a productos finales con un $\mathrm{pH}$ entre 7 y 8 ; valores más bajos del $\mathrm{pH}$ son indicativos de fenómenos anaeróbicos y de que el material aún no está suficientemente degradado. Posteriormente estos mismos autores estudiaron las relaciones $\mathrm{pH}$ aireación-microorganismos existentes en el proceso, y dedujeron que la degradación orgánica se inhibe a pH bajos, por lo que si el $\mathrm{pH}$ se mantiene por encima de 7,5 durante el proceso es síntoma de una buena descomposición.

El nitrógeno es un elemento esencial para la reproducción celular debido a la naturaleza proteica del protoplasma; se ha demostrado que la calidad de un proceso biodegradativo está directamente relacionada con su contenido de $\mathrm{N}$. El fósforo desempeña un papel fundamental en la formación de compuestos celulares ricos en energía, siendo necesario para el metabolismo microbiano (28). Durante el proceso de biodegradación se observaron mayores concentraciones de $\mathrm{N}\left(\mathrm{NO}_{3}{ }^{-}\right)$y $\mathrm{P}\left(\mathrm{PO}_{4}{ }^{3-}\right)$ en las etapas inicial $(<30$ días) y final $(>90$ días del proceso) (Figura 2) (Figura 3). Se comprueba entonces que, en general, entre el inicio y el final de la incubación se produce un aumento de las concentraciones de los distintos nutrientes, debido a la pérdida de materia orgánica de la masa a degradar (29) (30).

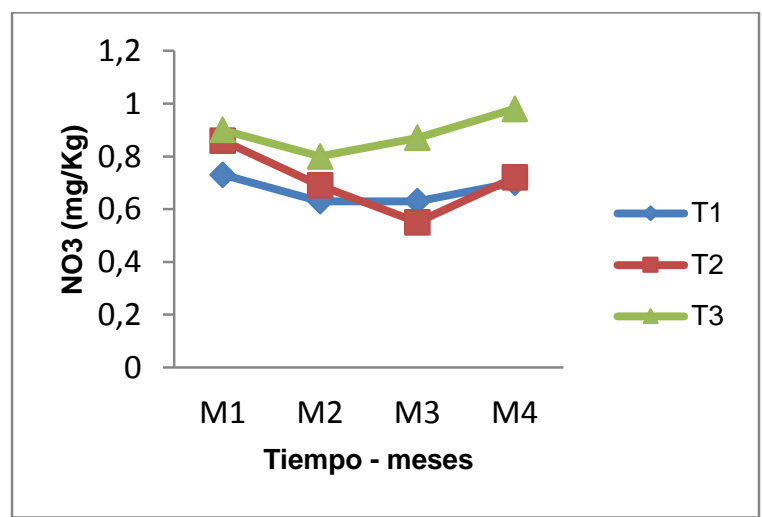

Figura 2. Variación de la concentración de $\mathrm{N}\left(\mathrm{NO}_{3}^{-}\right)$ en los tres terrarios durante el tiempo de biodegradación (120 días).
Situación que contrasta con el aumento en el crecimiento bacteriano (Figura 4) y la disminución de la concentración de aceite (Figura 5), las cuales se presentaron sin diferencias significativas $(p=$ $0,992$ y $p=0,250 ; p>0,05)$, en los tres terrarios durante el transcurso del tiempo de degradación. Se observa mayor crecimiento bacteriano en el terrario No 1 al igual que la mayor disminución de la concentración de aceite, lo cual pudo haber sido consecuencia de las mejores condiciones de humedad, $\mathrm{pH}$ y disponibilidad de nutrientes $(\mathrm{N}$ y $\mathrm{P})$, presentadas en dicha unidad de biodegradación.

La disminución de estos componentes inorgánicos durante la etapa intermedia del proceso de experimentación (>30 días y >90 días) puede tener como base de explicación de que el $\mathrm{N}$ es un nutriente que se caracteriza por estar sometido a una dinámica permanente de transformación y síntesis de carácter bioquímico en el que influyen procesos de ganancias y pérdidas del elemento en períodos relativamente cortos, además participa en fenómenos de absorción y fijación con coloides (31). En el caso del $P$ se presume que su disminución estuvo determinada por el consumo de este nutriente por las bacterias presentes en función de su metabolismo degradador (32).

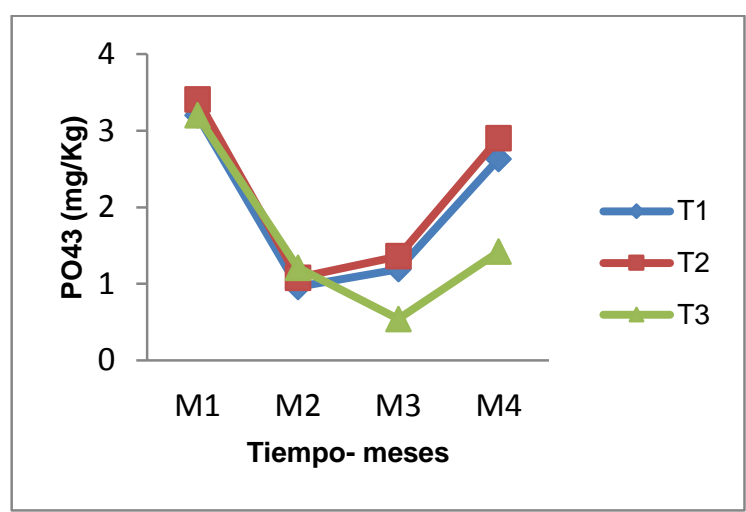

Figura 3. Variación de la concentración de $\mathrm{P}\left(\mathrm{PO}_{4}{ }^{3-}\right)$ en los tres terrarios durante el tiempo de biodegradación (120 días).

Aunque de manera general se presenta una correlación significativa entre la temperatura y la concentración de aceite $\left(R^{2}=0,563 ; p<0,01\right)$, la concentración de aceite y la del $N\left(R^{2}=0,554 ; p<\right.$ 0,01 ); el crecimiento bacteriano y la concentración de $N\left(R^{2}=-0,488 ; p<0,01\right)$ y el crecimiento bacteriano y la concentración de aceite $\left(R^{2}=-\right.$ $0,487 ; p<0,01)$; se pudo observar que en el 
terrario No 3 o de control, tanto el crecimiento bacteriano y la disminución de la concentración de aceite no fue tan eficiente, caso contrario se presentó en el terrario No 1 en donde se evidenció la mayor población microbiana y la mayor disminución de la concentración de aceite al finalizar el tiempo de análisis de la biodegradación. Se presume que lo anterior en consecuencia, que las excretas de ganado vacuno en su composición presentan mayores concentraciones de $\mathrm{N}(0,50 \%)$ y de $\mathrm{P}(0,23 \%)$ y de humedad $(80 \%)$ comparadas con las excretas de ganado caprino $\mathrm{N}(0,45 \%), \mathrm{P}$ $(0,13 \%)$ y humedad $(70 \%)(30)$, factores que propician un mayor crecimiento bacteriano y la actividad de los microorganismos aerobios (33).

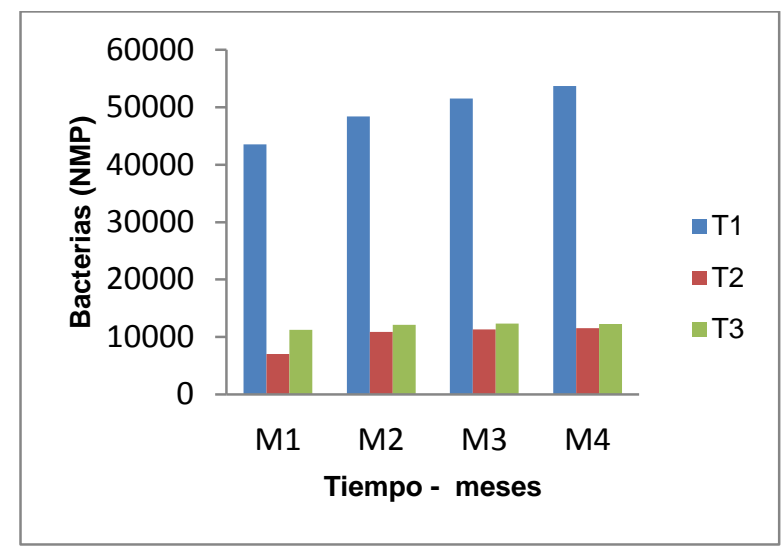

Figura 4. Variación del crecimiento bacteriano (NMP) en los tres terrarios durante el tiempo de biodegradación (120 días).

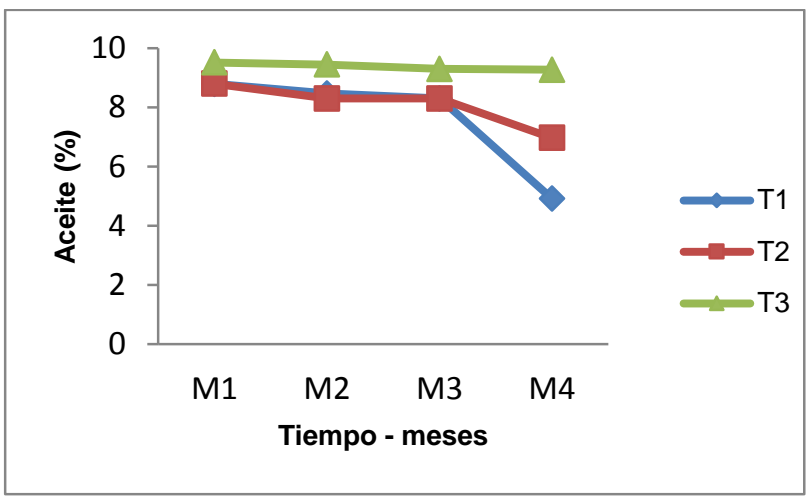

Figura 5. Variación de la concentración de aceite (\%) en los tres terrarios durante el tiempo de biodegradación (120 días).

Se puedo observar que los microorganismos se adaptan o desarrollan su metabolismo en función de los parámetros físico-químicos $(\mathrm{pH}$, temperatura, humedad) así como de los compuestos químicos que se encuentran en su ambiente inmediato. El petróleo y los hidrocarburos se encuentran naturalmente presentes en el suelo, lo que ha permitido a muchos microorganismos acostumbrarse a su presencia y utilizarlos para sobrevivir. En el caso de los hidrocarburos, las bacterias gram negativas parecen encontrarse más adaptadas a estas fuentes de carbono (34). Durante el estudio se pudo determinar que los géneros de microorganismos que degradan los hidrocarburos son Spseudomona, Achromobacter, Micrococcus y Bacillus. Estas especies tienen una acción degradadora efectiva de los derivados del petróleo al ingerirlo y emanar bioproductos que alteran las propiedades físico-químicas del aceite usado, acelerando su evaporación y biodegradación (35) (36)

\section{CONCLUSION}

A través de la biodegradación en terrarios estimulada con excreta de ganado vacuno se demuestra una viabilidad económica y ambiental como una alternativa de remediar y restaurar la contaminación de los suelos por aceites generados en cantidad considerable para el uso en general de hidrocarburos en cualquier tipo de actividad y que afecte el suelo.

La estimulación de la biodegradación con excreta de ganado vacuno demuestra ser muy efectiva en la recuperación de suelos contaminados por aceites, aparentemente es efectiva en condiciones controladas pero deben realizarse estudios en campo y en diferentes condiciones ambientales y de características del suelo para determinar su efectividad real, alcanzando un $65 \%$ de biodegradación en un tiempo de 120 días, mayor que la estimulada con excreta de ganado caprino (53\%); como consecuencia de factores determinantes del proceso como temperatura en promedio de $27^{\circ} \mathrm{C}$, humedad entre $11-20,60 \%$, $\mathrm{pH}$ entre $6,40-8,30$, la disponibilidad de nutrientes ( $N$ y $P$ ) y un crecimiento bacteriano. 


\section{REFERENCIAS BIBLIOGRAFICAS}

[1] CERREJÓN. Informe de Sostenibilidad 2010. Carbones del Cerrejón Limited. División de Comunicaciones. Centro de Información e Investigación. Bogotá, Colombia, 2011.

[2] Gualdrón, R. CERREJON, Hacia la rehabilitación de tierras intervenidas por minería a cielo abierto. Panamericana Formas e Impresos S.A Ed. Bogotá, 2010.

[3] Colla, T., Andreazza, R., Bücker, F., Souza M., Tramontini, L., Prado G., Frazzon, A., Camargo, F., y Bento F. Bioremediation assessment of diesel-biodiesel-contaminated soil using an alternative bioaugmentation strategy. Environ. Sci. Pollut. 21 (4), 25922602, 2014.

[4] González, V. Evaluación de la actividad biológica y potencial de biodegradación de un suelo contaminado por hidrocarburos (Tesis de Licenciatura). División Académica de Ciencias Biológicas. Universidad Juárez Autónoma de Tabasco, Villahermosa, Tabasco, México, 2014.

[5] Canals, M. Biorremediación de suelos contaminados por hidrocarburos: caracterización microbiológica, química y ecotoxicológica. (Tesis doctoral). Universidad de Barcelona, Facultad de Biología, Departamento de Microbiología. España, 2005.

[6] Flórez, C. Transformación de los aceites usados para su utilización como energéticos en procesos de combustión. En: Escenarios Y Estrategias. Bogotá, 8, 28 - 32, 2001.

[7] Leavy, J., Colwell R. Microbial Hydrocarbons in the Microbiological Reviews, 1990
[8] ASTM. Standard guide for risk-based corrective action applied at petroleum release sites E1739-95. American Society for Testing and Materials. Manual. West Conshohocken, EUA, 53 pp. 2010.

[9] Álvaro, C., Arocena, L., Martínez, M., Nudelman, N. Biodegradación aerobia de fracciones de hidrocarburos provenientes de la actividad petrolera en un suelo de la región Patagonia Norte, Argentina. Rev. Int. Contam. Ambie. 33 (2) 247-257,2017. DOI: 10.20937/RICA.2017.33.02.06.

[10] Benavente, G. Aceite Lubricante Usado. Bravo Energy Chile S.A. Boletín № 2. Junio 1999.

[11] Acuña, A., Pucci, G., Morales, M'

Pucci, O. Biodegradacion de petróleo y sus derivados por la comunidad bacteriana en suelo de La Patagonia Argentina. Revista de la Sociedad Venezolana de Microbiología, 30(1):29-36, 2011.

[12] Voroney, R. The soil habitat. Soil microbiology, ecology, and biochemistry, 2007.

[13] Díaz, M., Grigson, S., Burgess, J. Uso de un consorcio bacteriano extremo-halotolerante para la biodegradación de crudo en ambientes salinos. Revista Colombiana de Biotecnología. 4(1): 36-42. 2002.

[14] López, M. Reseña de Símbolos y Patrimonios Naturales y Culturales de La Guajira. 2010

[15] IGAC- Instituto Geográfico Agustín Codazzi. Estudio Semidetallado de Suelos y Zonificación de Tierras en la Media y Baja Guajira. Escala 1:25.000. Imprenta Nacional. Bogotá, 2012. 
[16] IGAC- Instituto Geográfico Agustín Codazzi. Métodos Analíticos del laboratorio de Suelos. Bogotá, 2006.

[17] López, F. La degradación de los suelos por erosión hídrica: métodos de estimación. Universidad de Murcia. España, 2011.

[18] Braibant C. Estudio del potencial de degradación de los hidrocarburos por Acinetobacter sp. Y Pseudomonas putida para su aplicación en la biorremediación de suelos contaminados. instituto tecnológico de Costa Rica escuela de biología. Ingeniería en biotecnología. 2004.

[19] Martínez, A., Pérez, M., Pinto, J., Gurrola, B., Osoria, A. Biorremediación de suelo contaminado con hidrocarburos empleando lodos residuales como fuente alterna de nutrientes. Rev. Int. Contam. Ambient. 27 (3). 2011

[20] IGAC- Instituto Geográfico Agustín Codazzi. Propiedades físicas de los suelos. Segunda Edición. Bogotá, 1990.

[21] Pardo, J., Perdomo, M., Benavides, J. Efecto de la adición de fertilizantes inorgánicos compuestos en la degradación de hidrocarburos en suelos contaminados con petróleo. Nova - publicación científica, 2 (2), 43-49, 2004.

[22] López, M., Lerena, P. Recuperación Asistida con Microorganismos. Microbios de Venezuela C.A. Ciudad Ojeda. 240-5, 1993.

[23] Ecopetrol- Compañía Colombiana de Petróleo. Cartilla práctica para el manejo de residuos en las instalaciones del distrito de oleoducto. Bogotá, 1993.
[24] Ekinci, K., Keener, H., Elwell, D. Effects of aeration strategies on the composting process: Part I. Experimental studies. Trans. ASAE, 47 (5), 1697-1708, 2004.

[25] Eweis, J., Ergas, S., Chang, D., Schroeder, E. Principios de Biorrecuperación: Tratamientos para la descontaminación y regeneración de suelos y aguas subterráneas mediante procesos biológicos y fisicoquímicos. Mc Graw Hill/ Interamericana de España. Madrid, España, 1999.

[26] Paul, E. Soil Microbiology, Ecology and Biochemistry. Third edition. Academic Press, Inc. Elsevier. USA, 2007.

[27] Frioni, F. Microbiología: básica, ambiental y agrícola. Ed. Orientación Gráfica, ed. Pra ed. 2011.

[28] Suler, D., Finstein, S. Effect of Temperature, Aeration, and Moisture on $\mathrm{CO}_{2}$ Formation in Bench-Scale, continuosly Thermophilic Composting of Solid Waste. Appl. Environ. Microbiol., 33 (2), 345-350. 1977.

[29] Daims, H. y Wagner, M. The microbiology of nitrogen removal. In: Microbial ecology of activated sludge, R. Seviour y N. Halkjaer (ed.), IWA publishing, London, 259-280, 2010.

[30] Díaz, M., Jiménez, L., Cabrera, F., De Bertoldi, M. Using a second order polynomials model to determine the optimum vinasse/grape marc ratio for in vessel composting. Compost Sci. Util., 12 (3), 273-279, 2004.

[31] Michel, F., Pecchia, J., Rigot, J. Mass and nutrient losses during the composting of dairy manure amended with sawdust or straw. Compost Sci. Util., 12 (4), 323-334, 2004. 
[32] Claros, J. Estudio del proceso de nitrificación y desnitrificación vía nitrito para el tratamiento biológico de corrientes de agua residual con alta carga de nitrógeno amoniacal (Tesis Doctoral). Universidad Politécnica de Valencia. Departamento de ingeniería hidráulica y medio ambiente. España. 2012.

[33] Cassidy, D. y Belia, E. Nitrogen and phosphorus removal from an abattoir wastewater in a SBR with aerobic granular sludge. Wat. Res. 39(19), 4817-4823, 2005.

[34] Miller, R. W y Donahue, R. L.Soils in our environment. Prentice Hall. 7a Edición. 649 pp. 1995.

[35] Volque, T., Velsco, J. Biodegradación de hidrocarburos del petróleo en suelos intemperizados mediante composteo. Dirección en Investigación en Residuos y Proyectos Regionales. Secretaría de Medio Ambiente y Recursos Naturales. México, 2003.

[36] Bossert, I., Bartha, R. The fate of petroleum in soil ecosystem. In: Petroleum Microbiology. Atlas, R. (Ed.). Macmillan Publishing Co. 1984. 